\title{
O VOZEAMENTO/DESVOZEAMENTO VARIÁVEL DAS OCLUSIVAS BILABIAIS EM PORTUGUÊS NUMA COMUNIDADE TEUTO-BRASILEIRA E O RELACIONAMENTO EM REDE DOS FALANTES
}

\author{
THE VARIABLE VOICING/DEVOICING OF BILABIAL PLOSIVES IN PORTUGUESE \\ IN A BRAZILIAN COMMUNITY OF GERMAN DESCENT AND THE NETWORK \\ RELATIONSHIP OF THE SPEAKERS
}

\author{
Adalberto Ayjara Dornelles Filho \\ Professor do Departamento de Matemática e Estatística - UCS \\ aadornellesf@gmail.com \\ Elisa Battisti \\ Professora do Programa de Pós-Graduação em Letras - UFRGS \\ battisti.elisa@gmail.com \\ Claudia Camila Lara \\ Doutoranda do Programa de Pós-Graduação em Letras - UFRGS \\ ccamilalara@gmail.com
}

RESUMO: A variação das oclusivas bilabiais no português brasileiro em contato com a língua minoritária alemã, o Hunsrückisch, verifica-se em Glória, comunidade teutobrasileira da zona rural do município de Estrela/RS. O fenômeno linguístico pode instanciar-se com o desvozeamento das oclusivas (baile paile; trabalho trapalho) ou

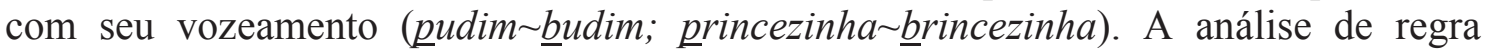
variável (LABOV, 1972) de dados de entrevistas sociolinguísticas (LARA, 2013), submetidos ao pacote computacional VARBRUL, versão GoldVarb X, revelou que a aplicação é inferior a 5\%, condicionada pelos informantes mais velhos, o que aponta a regressão da regra. O estudo da rede social dos informantes (MILROY, 1987, 2002) mostra que, nas redes densas e multiplexas, os falantes mais velhos não difundem o processo aos mais jovens, mesmo que com eles tenham laços fortes. A observação participante na comunidade, baseada no estudo etnográfico de Eckert (2000), revela que os sujeitos mais velhos realizam práticas sociais predominantemente locais, práticas que promovem o contato Hunsrückisch-português, enquanto os jovens deslocam-se diariamente para centros urbanos a fim de trabalhar, o que fomenta o monolinguismo em português.

PALAVRAS-CHAVE: Linguística em progresso; Vozeamento/desvozeamento das oclusivas bilabiais; Práticas sociais. Redes sociais.

ABSTRACT: The variation of bilabial plosive consonants in Brazilian Portuguese in contact with a German minority language, Hunsrückisch, is studied in the speech of Glória, a countryside community in Estrela city, Rio Grande do Sul, Brazil. The voiceless plosives alternate with the voiced ones (baile $\sim$ paile 'ball'; trabalho trapalho,

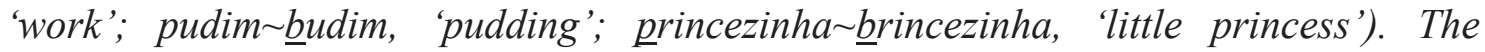
variable rule analysis (LABOV, 1972) of data from 24 sociolinguistic interviews (LARA, 2013) with the VARBRUL programs, GoldVarb X version, shows that the application rate is very low and that the process is favored by old speakers, indicating the regression of the rule. The analysis of the social network of the informants (MILROY, 1987, 2002) shows that the network is dense and multiplex, but the old speakers do not 
spread the process to the young ones. The ethnographic study (ECKERT, 2000) reveals that the social practices of old speakers are localized, favoring the HunsrückischPortuguese contact, while the social practices of young speakers are not, favoring the exclusive use of the Portuguese language.

KEYWORDS: Variation and change; The variable voicing/devoicing of bilabial plosives; Social practices; Social networks.

\section{INTRODUÇÃO}

A língua minoritária alemã, Hunsrückisch, é falada em regiões de colonização alemã no Rio Grande do Sul, Santa Catarina, Paraná e, recentemente, na região amazônica. A vinda dos imigrantes alemães para o Brasil foi motivada pelas oportunidades de trabalho e prosperidade econômica. Partindo de diferentes províncias, cidades e aldeias germânicas (Pomerânia, Westfalen, Hunsrück, Swabia e regiões circunvizinhas), dirigiram-se a áreas do interior no Sul do Brasil (RASO, MELLO e ALTENHOFEN, 2011).

Os alemães chegaram ao Rio Grande do Sul em 1824 e, a partir de então, organizaramse em colônias. Segundo o Instituto Brasileiro de Geografia e Estatística (IBGE, 2010), a fundação do futuro município de Estrela, investigado neste estudo, teria provavelmente ocorrido por volta de 1856, quando começou a colonização, dos imigrantes alemães, em terras do proprietário Coronel Vitorino José Ribeiro.

Do contato linguístico entre o português e o Hunsrückisch resultaram características que têm estereotipado o português falado em comunidades com descendentes de imigrantes alemães. É o caso da alternância tratada no presente artigo, entre as oclusivas bilabiais. Diz-se, de maneira bastante alusiva, que "os falantes de Hunsrückisch trocam as letras": realizam [b], oclusivo vozeado, em lugar [p], oclusivo desvozeado (pudim $\sim$ budim,

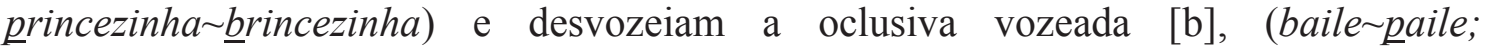
trabalho trapalho). Segundo Gewehr-Borella e Altenhofen $(2012$, p. 2), a variação do uso das oclusivas bilabiais /p b/ "configura uma marca social bastante estigmatizada, com conotações negativas relacionadas aos falantes de línguas de imigração alemã, vista como "fala de colono"".

O português está em contato com o Hunsrückisch na comunidade de Glória, localizada na zona rural do município de Estrela, situado na região do Vale do Taquari, Rio Grande do Sul. Segundo estimativas dos dados de 2010 do IBGE, Estrela dista $93 \mathrm{~km} \mathrm{da}$ capital, Porto Alegre, e tem 30.619 habitantes, destes, 4.706 residem na zona rural ${ }^{1}$. A Figura 1 apresenta a localização de Estrela, Porto Alegre e o Rio Grande do Sul em relação ao Brasil.

\footnotetext{
${ }^{1}$ Disponível em: http://ibge.gov.br. Acesso em 06 jan. 2013. 
Figura 1 Localização dos municípios de Estrela e Porto Alegre, e do Rio Grande do Sul em relação ao Brasil

Fonte: IBGE (2013)

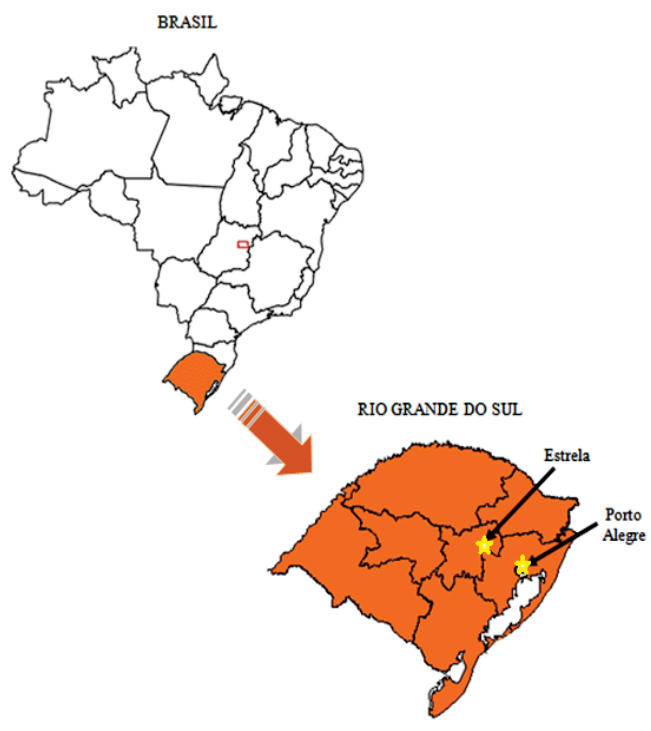

Lara (2013) investigou a variação das oclusivas no português falado em Glória. Este artigo é parte dessa investigação. O artigo traz a análise de regra variável (LABOV, 1972) e a análise da rede social (MILROY, 1987, 2002) dos informantes. Com elas, será possível afirmar que a variação das oclusivas está em regressão na comunidade, em razão das práticas sociais locais.

\section{PRESSUPOSTOS TEÓRICOS}

Os falantes de qualquer língua, ao se comunicarem, utilizam-se de formas linguísticas variadas. Sons, vocábulos e estruturas sintáticas podem ser realizados de diferentes formas, sem alteração de significado. Por essa razão, uma variedade linguística é concebível como um conjunto de variantes que coocorrem em uma dada língua (BERRUTO, 2010).

Para Labov (1972), os membros de uma comunidade de fala, ao compartilharem normas de uso, configuram padrões e realizam variação de forma estratificada na fala. Segundo Guy (2000), três características são definidoras para comunidade de fala: as características linguísticas compartilhadas e usadas na comunidade, mas não fora dela (palavras, sons ou construções gramaticais); a densidade de comunicação interna relativamente alta (entre os indivíduos da comunidade) e as normas compartilhadas (atitudes em comum sobre o uso da língua, a direção da variação estilística e avaliações sociais a respeito das variáveis linguísticas).

$\mathrm{Na}$ comunidade de fala pesquisada, foram identificados subgrupos, estudados como comunidades de prática, como fez Eckert (2000). Conforme Eckert (2000), os membros de uma comunidade de prática engajam-se a ela como a uma corporação. É um grupo de pessoas que busca alcançar objetivos comuns. As práticas linguísticas são uma dentre outras práticas realizadas em grupo. Nessas práticas, as variantes adquirem valor social. Os indivíduos, participando de forma marginal ou central, constroem identidades 
(personae) nessas comunidades, e as características da fala contribuem para essa construção. Categorias sociais como classe, idade, etnia, gênero são produzidas e reproduzidas nas comunidades de prática.

Lara (2013) identificou dez atividades comunitárias de Glória passíveis de ser analisadas como comunidades de prática: escola, coral, bolão, ginástica, teatro, grupo de $3^{\mathrm{a}}$ idade, apostolado da oração, vôlei, clube de mães e igreja.

Battisti et al. (2007) embasam em Eckert (2000) a análise da palatalização (tia tchia, dia djia) variável que realizam num pequeno município gaúcho, Antônio Prado. Embora Antônio Prado seja comunidade ítalo-brasileira, em muito se assemelha a comunidades do interior do estado fundadas por imigrantes europeus, como é o caso de Estrela. Nelas, há comunidades de prática sustentadoras das relações em rede dos indivíduos, voltadas ao relacionamento familiar, às atividades de trabalho, às práticas religiosas, principalmente. As redes, por sua vez, têm potencial para funcionar como processos sociais difusores da variação e mudança linguística (MILROY, 1987). Em Antônio Prado, a palatalização moderada (29\%) apresenta indícios de que vá progredir na comunidade, embora as redes, densas e multiplexas, nucleadas por indivíduos de faixas etárias mais velhas, refreiem o avanço do processo. Isso pode ser o que acontece em Glória com as oclusivas: as redes, se densas e multiplexas, podem estar refreando o avanço do português, fazendo com que persista o traço de contato com o Hunsrückisch, hoje de realização pouco frequente.

Conforme Milroy (2002), nas redes sociais densas, há um grande número de indivíduos conectados, as pessoas conhecem umas às outras. Se, além disso, elas se conectam por mais de uma forma de ligação, formam uma rede social multiplexa. É o caso de vizinhos que são também colegas de trabalho, por exemplo. Milroy (1987, p. 139) afirma que "a densidade e multiplexidade são excelentes indicadores das pressões sobre uma pessoa a adotar normas e valores, incluindo as normas linguísticas e os valores da comunidade local”.

Blake e Josey (2003) estabeleceram uma forma de mensurar o grau de interação em rede entre os informantes: o grau (1) corresponde a uma situação de intensa comunicação entre os indivíduos, diariamente no trabalho, escola ou em casa. O grau (2) atribui-se a uma forte relação, uma comunicação regular entre os indivíduos. O grau de relacionamento (3) está para uma relação "entre amigos", de conversa ocasional, e o grau (4) é o dos indivíduos que se conhecem, porém não há um contato dinâmico entre eles. Um quinto grau foi considerado, marcado com sinal negativo (-), indicando que a relação desses indivíduos foi rompida em algum momento.

Battisti et al. (2007) adaptaram a escala proposta por Blake e Josey (2003) no estudo de Antônio Prado, lidando com três graus de interação, esses motivados pela sócio-história e cultura locais. Os graus cobrem relacionamentos familiares, entre colegas de trabalho, amigos, conhecidos.

Neste artigo, como fizeram Battisti et al. (2007), baseamo-nos em Blake e Josey (2003) para analisar em graus a rede social dos informantes de Glória. Como veremos, a rede social resultante da interação dos indivíduos nas diferentes subcomunidades explica a 
forte tendência ao desaparecimento da variação das oclusivas, traço de contato do português com o Hunsrückisch.

\section{PROCEDIMENTOS METODOLÓGICOS}

A análise quantitativa de dados conforme a Teoria da Variação (LABOV, 1972) é o que se denomina análise de regra variável. Essa e a análise de rede social, de Milroy (1987, 2002), são realizadas no estudo. Como as redes sociais estabelecem-se entre indivíduos que interagem em comunidades de prática (ECKERT, 2000), essas unidades serão consideradas no estudo.

Os dados submetidos à análise de regra variável foram levantados de 24 entrevistas sociolinguísticas com informantes de Glória. A realização das entrevistas organizou-se de forma a haver um primeiro contato com os moradores da comunidade através de uma conversa, cujo objetivo era o de saber se a pessoa gostaria de participar e colaborar, espontaneamente, da pesquisa, descrita então como um estudo da cultura local. Cada entrevistado indicou um outro e, eventualmente, disponibilizou-se a contatá-lo. Uma ficha social foi preenchida com informações de cada informante, ficha essa que incluiu o registro do conhecimento (ou não) dos já anteriormente entrevistados, e o grau de conhecimento. Após, foi realizada entrevista - gravada, semi-estruturada, conforme um roteiro, procurando assemelhar-se o máximo possível a uma conversa entre entrevistador e entrevistado.

Os 24 informantes de Glória distribuíram-se em três faixas etárias (15 - 30 anos, 31 46 anos, 47 anos ou mais), três níveis de escolaridade (ensino fundamental, ensino médio e ensino superior) e dois gêneros (feminino e masculino).

\subsection{Análise de regra variável}

A análise de regra variável verifica os grupos de fatores favorecedores ou não do processo variável em questão. $\mathrm{Na}$ análise da variação das oclusivas, os grupos de fatores, linguísticos e extralinguísticos, considerados são os seguintes:

- Contexto precedente: vazio (_pouco); nasal (limpo); tepe (urbana); fricativa (disputa); vogal anterior (dependi); vogal central (rapadura); vogal posterior (sopa) e lateral alveolar (galpão) ${ }^{2}$;

- Contexto seguinte: vogal anterior (cabelo); vogal central (trabalha); vogal posterior (bonito); tepe (sempre); lateral alveolar (bloco); fricativa (pcisava); nasal (submissas) e oclusiva (optam) ${ }^{3}$;

\footnotetext{
${ }^{2}$ Em Glória, a vocalização variável da consoante lateral /l/, que transforma o $\mathrm{L}$ pós-vocálico em $\mathrm{U}$ (varal varaU) em muitos falares de português brasileiro, não é processo avançado, ainda se verificam muitas realizações da consoante sem vocalização. No exemplo galpão, captado de oitiva na comunidade, a consoante realizou-se como a lateral alveolar $/ 1 /$, ocorrência peculiar ao português de contato com falares dialetais alemães, como em Glória, e italianos no Rio Grande do Sul.

${ }^{3}$ No português de contato com o Hunsrückisch falado em Glória, verificam-se ocorrências como submissas e optam sem a epêntese vocálica variável (subimissas, opitam) característica de outros falares de português brasileiro. Por essa razão, controlaram-se os fatores nasal e oclusiva no contexto fonológico seguinte.
} 
- Sonoridade da consoante-alvo: é considerada variável quando a consoante vozeada pode sofrer desvozeamento (b bloco $\sim$ ploco) e a não vozeada, vozeamento (pudim $\sim$ budim);

- Tonicidade da sílaba: sílaba tônica (baile); sílaba pretônica (pudim) e sílaba postônica (município);

- Número de sílabas: palavras monossílabas (bom); dissílabas (bairro); trissílabas (trabalha) e polissílabas (abandonada);

- Gênero: feminino e masculino;

- Idade: 15 - 30 anos; 31 - 46 anos; 47 anos ou mais;

- Escolaridade: ensino fundamental; ensino médio; ensino superior;

- Bilinguismo: ativo (fala e entende dialeto alemão), passivo (entende, mas não fala o dialeto) e zero (não fala e não entende dialeto).

A análise é realizada com o pacote de programas computacionais VARBRUL, versão GoldVarb X.

\subsection{Análise de rede social}

Na investigação do relacionamento em rede e da influência das práticas sociais advindas das comunidades de prática dos informantes da pesquisa, identificaram-se comunidades de prática de Glória. Essa informação foi feita quando os informantes responderam ao questionamento sobre a participação em atividades comunitárias em Glória e sobre seu engajamento nessas atividades. Enumeraram-se, então, os grupos de que cada informante fazia parte, na ordem de maior para menor participação.

Na realização das entrevistas sociolinguísticas, obtiveram-se também informações sobre os graus de relacionamento entre os informantes. Adaptados da escala de Blake e Josey (2003) conforme os laços observados na comunidade de Glória, os graus considerados foram: 1A, relacionamento familiar (marido, esposa, filha/filho, irmã/irmão); 1B, vizinhos, amigos íntimos (próximos); 1C, relação de trabalho ou atividade nos grupos. No grau (2), as subdivisões são 2A, relação de parentesco (tia/tio, sobrinha/sobrinho, prima/primo); 2B, vizinhos, amigos que se encontram, geralmente, no final de semana; e $2 \mathrm{C}$, relação de trabalho ou atividade mensal (eventual). O grau (3) compreende 3A, relacionamento de familiares com pouca interação; 3B, vizinhos, amigos distantes; e $3 \mathrm{C}$, uma relação em que os informantes se conhecem, sabem uns dos outros e se localizam dentro da comunidade de Glória ou que, no passado, já participaram de atividades comuns, mas atualmente não interagem mais. $O$ Gráfico 1 apresenta a distribuição dos graus.

Gráfico 1 Graus de relacionamento em rede

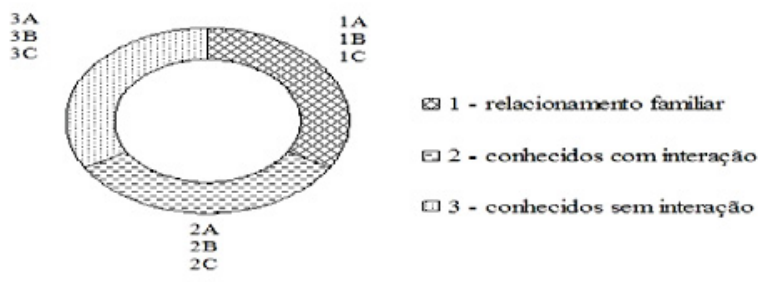

Fonte: Lara (2013) 


\section{RESULTADOS E DISCUSSÃO}

\subsection{Resultados da análise de regra variável}

Na operação do GoldVarb X, as variáveis contexto precedente, tonicidade da sílaba e bilinguismo foram rodadas em etapas diferentes. Esse procedimento justifica-se em função da ortogonalidade entre os grupos de fatores.

Do total de 14.189 contextos, houve apenas 223 ocorrências $(1,6 \%)$ de variação das oclusivas, principalmente do emprego da desvozeada em lugar da vozeada. Essa baixa proporção de aplicação indica que a realização em questão não resulta de um processo efetivamente variável. No entanto, o índice em si é expressivo porque permite afirmar que, se hoje há "troca" das oclusivas, o processo é residual. Persiste em piadas e no estereótipo que se criou do teuto-brasileiro falando português, mas é muito pouco frequente e há fortes indícios de seu desaparecimento. Os resultados da análise quantitativa devem, então, assim ser tomados: se há fatores que condicionam (e assim mantêm) esse emprego residual, quais são eles?

O programa estatístico apresentou a sonoridade da consoante-alvo, escolaridade, contexto precedente, bilinguismo, gênero e tonicidade da sílaba, como os grupos de fatores relevantes, na ordem da maior à menor relevância, o que consideraremos ao expor os resultados a seguir.

A variável sonoridade da consoante-alvo mostra que /b/ é o alvo da alternância $(0,91)$, como se vê na Tabela 1 .

Tabela 1 Sonoridade da consoante-alvo

\begin{tabular}{l|l|l|l}
\multicolumn{1}{c|}{ Fatores } & \multicolumn{1}{c}{ Aplicação/Total } & \% & Peso Relativo \\
\hline$/ \mathrm{b} /$ & $202 / 4481$ & 4,5 & 0,91 \\
\hline$/ \mathrm{p} /$ & $21 / 9708$ & 0,2 & 0,25 \\
\hline TOTAL & $223 / 14189$ & 1,6 & \\
\hline Input: 0,003 & \multicolumn{2}{c}{ significância: 0,000}
\end{tabular}

Quanto à escolaridade, o fator ensino fundamental condiciona a variação das oclusivas (Tabela 2). O ensino superior $(0,30)$ e o ensino médio $(0,15)$ desfavorecem a aplicação da regra variável.

Tabela 2 Escolaridade

\begin{tabular}{l|l|l|l}
\multicolumn{1}{c|}{ Fatores } & \multicolumn{1}{c|}{ Aplicação/Total } & \multicolumn{1}{c}{$\%$} & Peso Relativo \\
\hline Ens. Fundamental & $207 / 6468$ & 3,2 & 0,81 \\
\hline Ens. Superior & $12 / 4172$ & 0,3 & 0,30 \\
\hline Ens. Médio & $4 / 3549$ & 0,1 & 0,15 \\
\hline TOTAL & $223 / 14189$ & 1,6 & \\
\hline Input: 0,003 & \multicolumn{2}{c}{ significância: 0,000}
\end{tabular}

A Tabela 3 apresenta os resultados para contexto precedente: os fatores tepe alveolar $(0,99)$ e vogal central $(0,62)$ condicionam a aplicação da variável. As vogais anterior e posterior e a consoante nasal são desfavorecedoras.

Tabela 3 Contexto precedente

$$
\text { Fatores }
$$




\begin{tabular}{l|l|l|l}
\hline Tepe alveolar (urbana) & $22 / 61$ & 36 & 0,99 \\
\hline Vogal central (sabe) & $27 / 1490$ & 1,8 & 0,62 \\
\hline Vazio (_pouco) & $145 / 9024$ & 1,6 & 0,52 \\
\hline Vogais anterior (dependi) e posterior (sopa) & $18 / 1749$ & 1,0 & 0,46 \\
\hline Nasal (campo) & $11 / 1865$ & 0,6 & 0,29 \\
\hline TOTAL & $223 / 14189$ & 1,6 & \\
\hline Input: 0,003 & \multicolumn{2}{|c}{ significância: 0,000}
\end{tabular}

Os informantes bilíngues ativos (falam e entendem dialeto alemão) condicionam a variação das oclusivas $(0,70)$. Os bilíngues passivos (só compreendem, não falam) e zero (não compreendem, não falam), com peso relativo 0,33 e 0,06 , respectivamente, desfavorecem a regra. Os resultados estão na Tabela 4.

Tabela 4 Bilinguismo

\begin{tabular}{l|l|l|l}
\multicolumn{1}{c|}{ Fatores } & \multicolumn{1}{|c|}{ Aplicação/Total } & \% & Peso Relativo \\
\hline Ativo & $210 / 7961$ & 2,6 & 0,70 \\
\hline Passivo & $12 / 4889$ & 0,2 & 0,33 \\
\hline Zero & $1 / 1339$ & 0,1 & 0,06 \\
\hline TOTAL & $223 / 14189$ & 1,6 & \\
\hline Input: 0,003 & \multicolumn{2}{c}{ significância: 0,000}
\end{tabular}

A aplicação da regra variável é favorecida por informantes do gênero feminino, como se vê na Tabela 5.

Tabela 5 Gênero

\begin{tabular}{l|l|l|l}
\hline \multicolumn{1}{c|}{ Fatores } & \multicolumn{1}{|c|}{ Aplicação/Total } & \% & Peso Relativo \\
\hline Feminino & $172 / 7261$ & 2,4 & 0,61 \\
\hline Masculino & $51 / 6928$ & 0,7 & 0,38 \\
\hline TOTAL & $223 / 14189$ & 1,6 & \multicolumn{2}{c}{ significância: 0,000}
\end{tabular}

$\mathrm{Na}$ variável tonicidade da sílaba, verificou-se que a sílaba tônica $(0,58)$ é favorecedora da aplicação da regra variável e as sílabas pretônica $(0,46)$ e postônica $(0,35)$ são desfavorecedoras. Os resultados para esse grupo de fatores são apresentados na Tabela 6.

Tabela 6 Tonicidade da sílaba

\begin{tabular}{l|l|l|l}
\multicolumn{1}{c|}{ Fatores } & \multicolumn{1}{c|}{ Aplicação/Total } & \% & Peso Relativo \\
\hline Tônica (baile) & $111 / 5698$ & 1,9 & 0,58 \\
\hline Pretônica (pudim) & $84 / 6603$ & 1,5 & 0,46 \\
\hline Postônica (tempo) & $28 / 1888$ & 1,5 & 0,35 \\
\hline TOTAL & $223 / 14189$ & 1,6 & \\
\hline Input: 0,003 & \multicolumn{2}{c}{ significância: 0,000}
\end{tabular}

O condicionador da aplicação da regra variável quanto ao grupo de fatores contexto seguinte foi o fator vogal central $(0,66)$, como em trabalha. A vogal anterior, como em bicicleta, é neutra $(0,52)$ e os demais fatores, tepe alveolar $(0,43)$, como em brincar, e vogal posterior $(0,40)$, como em bonito, são desfavorecedores. A Tabela 7 mostra os resultados. 
Tabela 7 Contexto seguinte

\begin{tabular}{|c|c|c|c|}
\hline $\begin{array}{c}\text { Fatores } \\
\end{array}$ & Aplicação/Total & $\%$ & Peso Relativo \\
\hline Vogal central (trabalha) & $84 / 2984$ & 2,8 & 0,66 \\
\hline Vogal anterior (bicicleta) & $60 / 3917$ & 1,5 & 0,52 \\
\hline Tepe alveolar (brincar) & $36 / 3528$ & 1,0 & 0,43 \\
\hline Vogal posterior (bonito) & $37 / 3638$ & 1,0 & 0,40 \\
\hline TOTAL & $217 / 14067$ & 1,5 & \\
\hline
\end{tabular}

Na Tabela 8, as palavras dissílabas aparecem como favorecedoras da regra, com peso relativo de 0,55 , as palavras trissílabas e polissílabas ficaram neutras e monossílabas desfavoreceram a aplicação da regra variável $(0,36)$.

Tabela 8 Número de sílabas

\begin{tabular}{l|l|l|l}
\hline Fatores & Aplicação/Total & $\mathbf{\%}$ & Peso Relativo \\
\hline Dissílabas & $109 / 5599$ & 1,9 & 0,55 \\
\hline Trissílabas & $64 / 3884$ & 1,6 & 0,53 \\
\hline Polissílabas & $24 / 1934$ & 1,2 & 0,49 \\
\hline Monossílabas & $26 / 2772$ & 0,9 & 0,36 \\
\hline TOTAL & $217 / 14067$ & 1,5 & \\
\hline Input: 0,002 & \multicolumn{2}{c}{ significância: 0,005}
\end{tabular}

Os informantes mais velhos condicionam a aplicação da regra $(0,86)$, como se vê na Tabela 9.

Tabela 9 Idade

\begin{tabular}{l|l|l|l}
\hline Fatores & Aplicação/Total & $\mathbf{\%}$ & Peso Relativo \\
\hline 47 ou mais & $177 / 4833$ & 3,7 & 0,86 \\
\hline $31-46$ anos & $40 / 4904$ & 0,8 & 0,48 \\
\hline $15-30$ anos & $6 / 4452$ & 0,1 & 0,12 \\
\hline TOTAL & $217 / 14067$ & 1,5 & \\
\hline Input: 0,002 & \multicolumn{2}{c}{ significância: 0,005}
\end{tabular}

O conjunto de resultados indica que a variação das oclusivas é sustentada em Glória, em termos sociais, por bilíngues ativos com nível fundamental de escolaridade, mais de 47 anos de idade e do gênero feminino; em termos linguísticos, por dissílabos, sílaba tônica, consoante-alvo /b/ precedida de tepe e seguida de /a/.

\subsection{Resultados do estudo da rede social dos informantes}

A Figura 1 traz a matriz do relacionamento em rede dos 24 informantes da pesquisa, considerando-se os graus descritos na Seção 2. 
Figura 1 Matriz de relacionamento em rede dos informantes

\begin{tabular}{|c|c|c|c|c|c|c|c|c|c|c|c|c|c|c|c|c|c|c|c|c|c|c|}
\hline$n^{\prime}$ & $2 \sum$ & × & & & & & & & & & ल & & en: & & & & & & & & & ల్ల \\
\hline 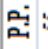 & $i \Sigma$ & $z$ & & & & & & & 8 & & ic & 囬 & , & & & 곡 & יח & & 瞣 & & & $x$ \\
\hline 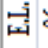 & & & & & & e & & & 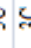 & C & 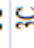 & $\therefore$ & ల & & & 고 & & & & & & 으으 \\
\hline 5 & $2 \Sigma$ & & & י্ল & ๓ & 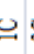 & : & 2 & 95 & 9 & ب & 으 & : & 2 & & (c) & I & & & & & ల \\
\hline 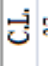 & $m \Sigma$ & & & પ્ટ & પ્ટ & 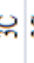 & e & & 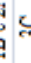 & ${ }_{N}$ & e & ' & œ & & & & 眊 & ర্d & $x$ & en. & & ల్ల \\
\hline 今) & $q \Sigma$ & & & ల. & પ્ત & 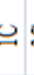 & 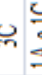 & 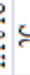 & 5 & $c$ & De & 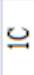 & & & 2 & D. & :0 & & ర్ల & 으 & & ల \\
\hline 4 & & & & & 囬 & ? & & 5 & $3 \leq$ & C & S & ల్ల & ' & : & मे & es & 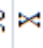 & ర্ন & ర్ల & द્व & & ల్ల \\
\hline (3) & & & & ' & 'ي & ల్ & D & 5 & 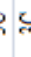 & 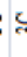 & ie & ల్ల & en. & e & & Dis & بn & 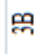 & 哭 & en. & & ర్ల \\
\hline . & $2 \geqslant$ & $z$ & & ల్ల & ల్ల. & s & ‘ & s. & 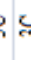 & 5 & i & ల్ల & ల్ల. & $\xi$ & & $4 \zeta$ & י & ల్ల & : & ' & & ల్ల \\
\hline 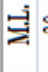 & & & & & व्व & $\nexists$ & $=$ & ? & 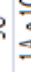 & ? & $=$ & 孚 & , & 2 ; & & 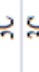 & ? & ల్ల & 営 & 罢: & & ల్ల \\
\hline : & & & 齐 & '. & $\begin{array}{l}\text { ¿ } \\
\text { @ } \\
\cong\end{array}$ & & ک & 8 & ac & 15 & & 브 & ' & 4 & & 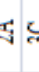 & 8 & ㄱ & & & & ల్ల \\
\hline & & & & & ي & లో & C & 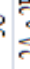 & 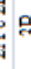 & dec & $m$ & 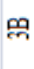 & 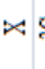 & e. & & 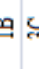 & יח & ల్ల & : & en & & ల్ల \\
\hline ต & & & & , & $\begin{array}{l}0 \\
\infty \\
\varrho\end{array}$ & 当 & p & & & 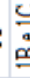 & 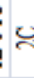 & 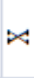 & : & 9 & & rec & יח & & : & & & \\
\hline $\overrightarrow{0}$ & & 充 & & 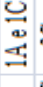 & . & $\vec{m}$ & & & 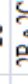 & & $x$ & ర্ন & স্ & e. & & & ?י্] & ల్ల & : & ' & & ర్ల \\
\hline & & 甹 & & , & 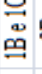 & D & \& & & & & $\stackrel{m}{\pi}$ & $\begin{array}{l}\stackrel{0}{\infty} \\
\cong\end{array}$ & : & 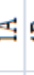 & a & 다 & יల & & m & פ & & ల్ల \\
\hline : & 只山 & 受 & & 무 & . & - & $m \leq$ & & & & ב & & & , & 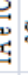 & & & & p & 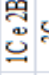 & & \\
\hline 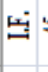 & 子山 & 挡 & & પ્ત & ర્d & C: & 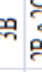 & & & & ర & 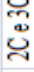 & 署 & 8 & & , & O্ন & & $\begin{array}{l}\text { 工 } \\
\text { } \\
\varrho \\
\varrho\end{array}$ & & & ల్ల \\
\hline की & 只 & 念은 & & m & m & $=$ & p & ? & & है & m & 으 & 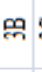 & : & 登 & $r$ & m & 일 & : & & & \\
\hline & F 山 & $\mapsto$ • & י & ల్ల & : & $9 ;$ & $x$ & ? & Pe & ¿ & : & স্ & u & , & & ك. & יల & ల్ల & : & : & & ల్ల \\
\hline & & 六 & & પ્ & પ્ન: & 4 & 25 & & & & m & & ల্ & & 9 & s & י & 5 & ? & 으 & & ల్ల \\
\hline गुं & 人山 & & ల్ల & $\begin{array}{l}\text { 茎 } \\
\text { 号: }\end{array}$ & & & & & & & 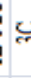 & $\cong$ & m & a & a & & 总 & & 勇 & פ & & ల్ల \\
\hline 赏 & 1 & - & & & 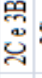 & & $=$ & & & & 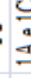 & & & Z & & & 墨 & & 总 & "్ల & & e \\
\hline & & & & ల్ల & ల్ల & & D. & & & & c & & , & & & : & ల్ల & ల్ల & : & ల్ల: & & 고 \\
\hline a & & $+x$ & & 을 & & & 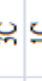 & & & & 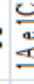 & 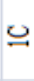 & & & & & & & ? & & & \\
\hline
\end{tabular}

Fonte: Lara (2013)

Todos os informantes de Glória se conhecem, como era de se esperar, dado o modo de ingresso na comunidade e de contato com os informantes (ver Seção 2). Os informantes 
têm laços fortes uns com os outros, nos graus de relacionamento 1A, B e C e 2A, B e C. Os laços fortes apresentam 220 ocorrências na matriz. Na Figura 2, esses laços são representados pelos traços da linha contínua grossa (_) A linha contínua fina $\left({ }_{-}\right)$ representa os relacionamentos de grau 2 e a linha tracejada (__) mais fina, a interação de grau 3 dos informantes. A linha pontilhada (...) conecta os informantes pelo grau 3C, ou seja, que apenas se conhecem, mas não interagem. A Figura 2, que representa as conexões em rede dos informantes, traz as iniciais dos mesmos em retângulos.

Figura 2 Rede social dos informantes

Rede: informante

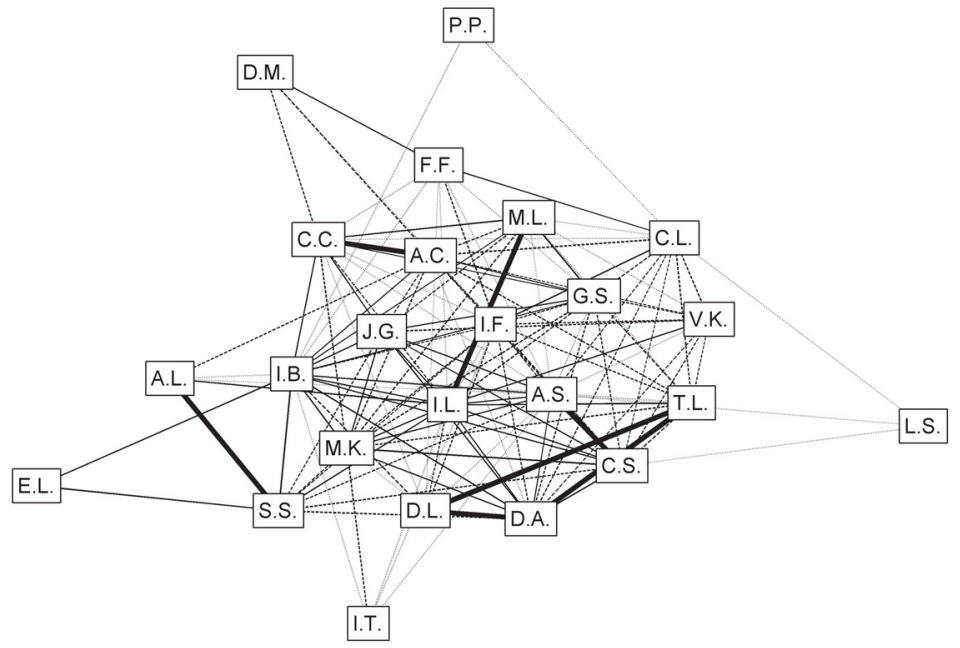

Fonte: Lara (2013)

Os graus (1) e (2) estabelecem-se em atividades comunitárias. A maioria dos indivíduos conecta-se múltiplas vezes, por participarem de mais de uma comunidade de prática ou serem familiares íntimos. Um exemplo disso são os informantes A.S. e C.S., que participam das comunidades de prática coral e igreja e são casados, portanto agregam-se aos graus 1A e 1C. Um exemplo que mescla os graus 1B e 2C é o dos informantes G.S e A.C., que são vizinhos e participam do grupo de teatro. Assim, pelo conhecimento mútuo e multiplicidade de conexões, pode-se afirmar que formam uma rede densa e multiplexa. Sua interinfluência é grande, o que afeta as práticas linguísticas.

As atividades comunitárias no coral, bolão, ginástica, teatro, grupo de $3^{\text {a }}$ idade, apostolado da oração, vôlei, clube de mães e igreja promovem o encontro dos informantes. Dentre essas comunidades de prática, o maior engajamento ocorre na igreja, apostolado da oração, teatro e coral. Uma delas está relacionada com a organização de Glória desde a sua fundação. Quando lá se estabeleceram, os imigrantes preocuparam-se em fundar uma igreja e uma escola. Assim, garantiram o ensino e os rituais religiosos que faziam parte de seus valores culturais.

Em torno da igreja, os informantes praticam atividades como: preparação da liturgia nas missas, catequese, ou frequentam as missas com regularidade. Os informantes mais 
velhos contam que, antigamente, no final das missas, havia um pequeno comércio na frente da igreja, pois era um dos momentos em que se encontravam para negociar a venda de produtos excedentes, a compra de materiais, terras ou insumos para o trabalho. Nesses momentos, os informantes falavam a língua em que se entendiam melhor, Hunsrückisch. Hoje, a fala ocorre predominantemente em português.

No apostolado da oração, apenas mulheres estão envolvidas em atividades mensais. Há a entrega de um folheto com mensagens cristãs para as sócias, que contribuem anualmente com uma quantia em dinheiro. O teatro é um grupo de pessoas que se envolve na encenação tradicional do Natal. A juventude católica de Glória foi a idealizadora do grupo. Os jovens organizaram uma encenação natalina para contribuir com a comunidade. Os membros do grupo, hoje, são diversas pessoas da comunidade, pois o grupo cresceu e incorporou mais personagens à apresentação. Geralmente, nos meses de novembro e dezembro, todos os domingos, à noite, os membros do grupo se reúnem para os ensaios da encenação. O coral canta nas missas, festas, eventos do município e em outras cidades. É o grupo de pessoas que interage com mais regularidade e frequência. Todas as terças-feiras se encontram para os ensaios.

A escola foi e continua sendo uma instituição muito importante para a comunidade. Os informantes mais velhos relatam que iam para a escola só falando o dialeto alemão, mas na escola era proibido falar alemão. Tinham de aprender o português. Essa proibição causou muitos problemas de adaptação à escola. Por isso, eles tiveram a preocupação de que seus filhos não passassem por situações constrangedoras, como aconteceu com eles. Logo, trataram de ensinar o português aos filhos desde cedo em casa, a fim de que fossem para a escola já sabendo português. Isso colaborou para que o português das gerações seguintes tivesse traços do contato com o Hunsrückisch, mas já minorados.

Verificou-se, durante as entrevistas sociolinguísticas e nas interações nas comunidades de prática, que os informantes, ao interagirem, praticam o bilinguismo. Por exemplo, isso ocorreu em uma situação em que um membro feminino do coral, com mais de 47 anos, chegou ao ensaio e cumprimentou os demais em dialeto alemão. Muitos responderam o cumprimento no dialeto, mas os mais jovens cumprimentaram em português e, imediatamente, o membro que acabara de chegar os cumprimentou em português. Outro exemplo ocorreu na festa da comunidade católica. J.G. pediu à C.S. uma cerveja em dialeto alemão, enquanto A.C. solicitou em português. A pesquisadora observou que, em diversos momentos da festa, no almoço, no sorteio de prêmios, na venda de bebidas, por exemplo, houve a alternância de código para o dialeto alemão, promovida predominantemente por informantes com mais de 47 anos, bilíngues ativos e de gênero feminino ${ }^{4}$. Tem valor para os mais velhos, enquanto os jovens optam por falarem quase exclusivamente em português.

Nas comunidades de prática, as redes sociais pessoais se estabelecem e as formas se difundem ou são refreadas. Nas comunidades de prática de que os jovens de Glória participam, não há praticamente a troca das oclusivas. Em Glória, embora os idosos sejam centrais na rede e mantenham laços fortes com indivíduos de menor idade, não influenciam os jovens. Esses parecem tomar como pares as pessoas de fora da comunidade de fala, ou seja, as pessoas com que se relacionam no trabalho nos centros

${ }^{4}$ Falar dialeto alemão é prática social de ambos os gêneros em Glória, mas predomina entre as mulheres. 
urbanos, onde não se promove o fenômeno linguístico em questão. Já nas comunidades de prática de que participam os informantes das faixas etárias 31 - 46 anos, 47 anos ou mais, a troca das oclusivas bilabiais ainda ocorre. Na Figura 3, observa-se o número de trocas por informante.

Figura 3 Número de trocas das oclusivas bilabiais

Rede: Número de trocas $/ \mathrm{p}, \mathrm{b} /$

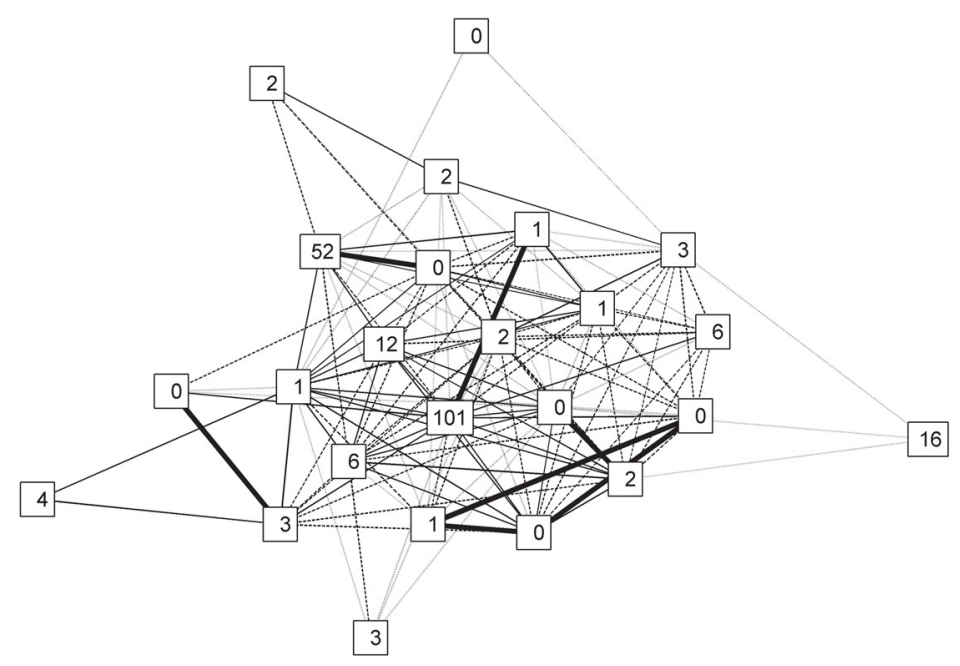

Fonte: Lara (2013)

$\mathrm{Na}$ Figura 3, vê-se que só dois informantes realizam mais de 50 trocas. Dois informantes realizam entre 10 e 20 trocas. Os demais 20 informantes realizam menos de 10 trocas, mesmo que conectados por laços fortes aos informantes que mais aplicam a regra. Não se verifica aproximação no número de trocas realizadas por esses informantes.

O informante que realizou 101 trocas é do gênero feminino, com mais de 47 anos, tem o menor nível de escolaridade (ensino fundamental), sua ocupação é local, e é aposentado. Os informantes das suas relações mais íntimas, que realizaram apenas entre uma e duas trocas, são do gênero feminino e masculino, encontram-se nas faixas etárias de 15 a 30 anos e 31 a 46 anos, têm ensino médio e superior e suas ocupações são não-locais. Isso indica que os informantes falam diferentemente em razão, principalmente, do contato com o português da zona urbana, onde trabalham.

Na Figura 4, está a proporção de aplicação da regra variável por informante, que é baixa entre os jovens, situados na periferia da rede. 
Figura 4 Proporção de trocas das oclusivas bilabiais

Rede: Proporção de trocas $/ p, b /$

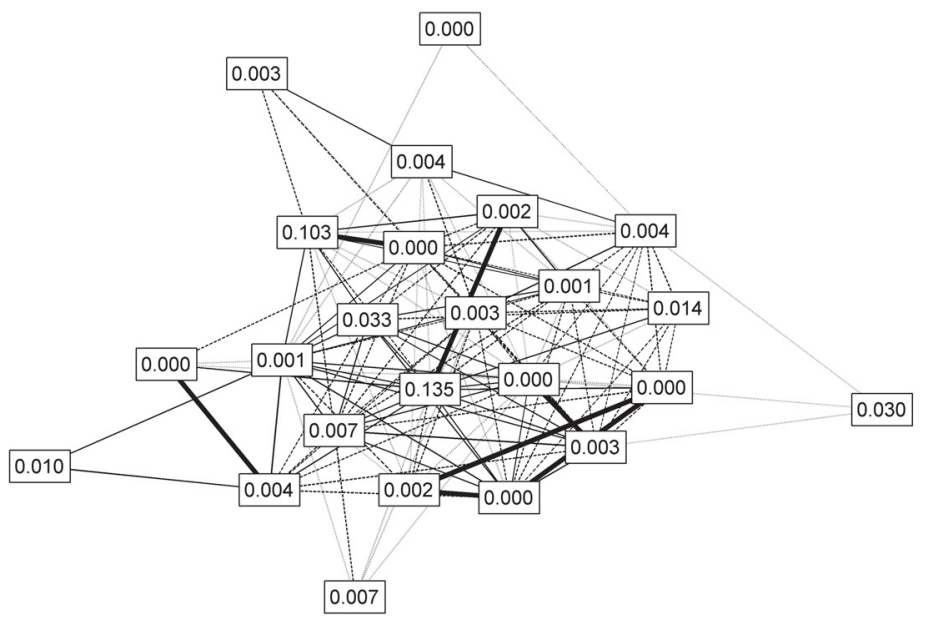

Fonte: Lara (2013)

Quatorze dos 24 entrevistados têm ocupações não-locais, deslocam-se para outros lugares a fim de desenvolverem outras atividades profissionais. Afirmam que, na comunidade, não há trabalho para todos e nem todos os tipos de trabalho que gostariam de executar.

Outros informantes destacam que precisam deslocar-se para o centro urbano ou para outros municípios da Região do Vale do Taquari a fim de trabalhar em diversas profissões que não se encontram na localidade de Glória. No entanto, os informantes que se deslocam para outros lugares praticam atividades locais quando possível, seja pelo menos no final do dia, quando retornam para casa, ou nos finais de semana. Esta característica é própria das ocupações categorizadas como locais: trabalham na comunidade em atividades agrícolas e em casa em algum momento do dia ou da semana. Por isso, há sete informantes que afirmaram que têm ocupação local e nãolocal.

Sete informantes alegam, além de estarem aposentados, desenvolverem, mesmo que informalmente, outras atividades, como o serviço de faxina e jardinagem e atividades locais na agricultura familiar.

Quatro informantes trabalham na agricultura e/ou em casa. Não desenvolvem outras ocupações e sobrevivem da agricultura. No Gráfico 3, estão distribuídos o número de informantes por ocupação. 
Gráfico 3 Ocupação por número de informantes

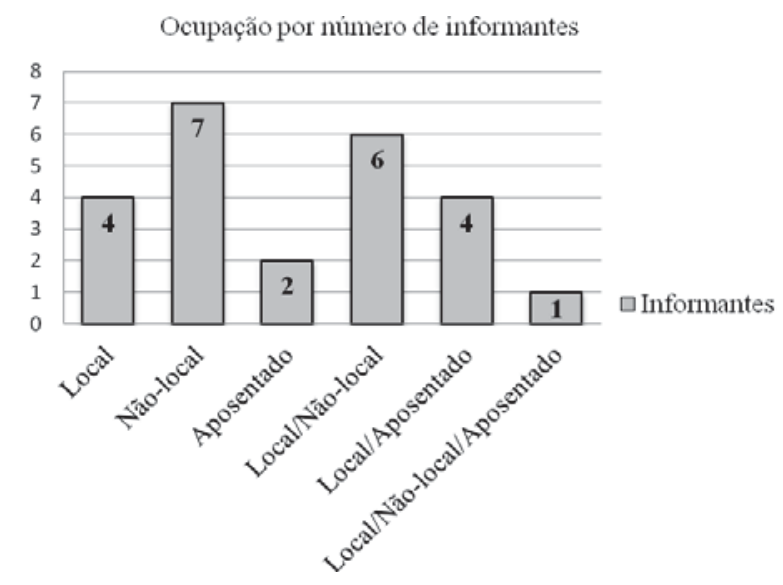

Fonte: Lara (2013)

O grupo exclusivamente não-local é o mais numeroso. As mulheres permanecem mais nas atividades locais, pois os homens, ainda, são os que mais se dirigem aos centros urbanos em busca de trabalho diversificado. Possivelmente é por essa razão que, na análise quantitativa (de regra variável, Seção 3.1), o gênero figure como favorecedor/sustentador da regra.

\section{CONCLUSÃO}

A análise de regra variável revelou um índice bastante baixo de variação das oclusivas $(1,6 \%)$, indicando que a variação das oclusivas em Glória não resulta de um processo efetivamente variável. É traço residual, em português, do contato com o Hunsrückisch, e há fortes indícios de que em breve desapareça. Os fatores que condicionam (e assim mantêm) esse emprego residual são, em termos sociais, bilíngues ativos com nível fundamental de escolaridade, mais de 47 anos de idade e do gênero feminino; em termos linguísticos, dissílabos, sílaba tônica, consoante-alvo /b/ precedida de tepe e seguida de /a/.

A análise da rede social dos informantes mostrou que, em Glória, embora os idosos, bilíngues Hunsrückisch-português e promotores da variação das oclusivas, sejam centrais na rede e mantenham laços fortes com os jovens, não influenciam a fala dos jovens. Isso se deve às práticas sociais realizadas pelos jovens, essencialmente nãolocais, práticas essas em que predomina o monolinguismo-português e que têm efeitos sobre sua fala.

A análise de regra variável e a de rede social mostraram-se importantes por revelarem que o processo de variação das oclusivas bilabiais $/ \mathrm{p}$ b/ está em desaparecimento na comunidade investigada e por mostrarem razões para esse desaparecimento. É mudança linguística em progresso o que se verifica em Glória, mudança essa que estudos futuros poderão confirmar. 


\section{REFERÊNCIAS}

BATTISTI, E. et al. Palatalização das oclusivas alveolares e a rede social dos informantes. Revista Virtual de Estudos da Linguagem - REVEL. v. 5, p. 01-29, 2007. Disponível em $<$ http://www.revel.inf.br>. Acesso em: 09 set. 2012.

BERRUTO, G. Identify dimensions of linguistic variation in a language space. In: AUER, P.; SCHMIDT, J. E. (ed.). Language and space: theories and methods. Berlin/New York: de Gruyer, 2010. p. 226-241.

BLAKE, R.; JOSEY, M. The /ay/ diphthong in a Martha's Vineyard community: what can we say 40 years after Labov? Language in Society, n. 32, v. 4, p. 451-485, 2003.

ECKERT, P. Linguistic variation as social practice. Oxford, Blackwell, 2000.

GEWEHR-BORELLA, S.; ALTENHOFEN, C. V. Macroanálise pluridimensional da variação de consoantes oclusivas do português por falantes de hunsriqueano. IN: Seminário Internacional de Fonologia, IV, 2012, Porto Alegre. Anais... Porto Alegre: Ed. Instituto de Letras/UFRGS, 2012, p. 1-16. Disponível em $<$ http://www.pucrs.br/eventos/fonologia/>. Acesso em: 09 ago. 2012.

GUY, R. G. A identidade linguística da comunidade de fala: paralelismo interdialetal nos padrões de variação linguística. Organon, v. 14, n. 28-29, p. 17-32, 2000. Disponível em <http://seer.ufrgs.br/organon/article/view/30194/18703>. Acesso em: 28 nov. 2012.

IBGE (Instituto Brasileiro de Geografia e Estatística). IBGE Cidades: Histórico de Estrela, RS. Disponível em <http://cod.ibge.gov.br/11S2>. Acesso em 16 dez. 2013.

LABOV, W. Sociolinguistic patterns. Philadelphia: University of Philadelphia Press, 1972.

LARA, C. C. Variação fonológica, redes e práticas sociais numa comunidade bilíngue português-alemão do Brasil meridional. 2013. 105 f. Dissertação (Mestrado em Letras) - Programa de Pós-Graduação em Letras. Universidade Federal do Rio Grande do Sul, Porto Alegre, 2013.

MILROY, L. Language and Social Networks. 2 ed. Oxford, Blackwell, 1987.

; L. Social Networks. In: CHAMBERS, J. K.; TRUDGILL, P.; SCHILLINGESTES, N. Eds. The handbook of language variation and change. Oxford Blackwell Publishing, 2002.

RASO, T.; MELLO, H.; ALTENHOFEN, C. V. Os contatos linguísticos e o Brasil Dinâmicas pré-históricas, históricas e sociopolíticas. In: MELLO, H.; ALTENHOFEN, C. V.; RASO, T. (org.). Os contatos linguísticos no Brasil. Belo Horizonte: Editora UFMG, 2011.

Recebido: $15 / 06 / 2013$

Aceito: 30/08/2013 